\title{
Research on Design Technology of Green Building for Environmental Protection
}

\author{
Li Xu, Bin Zhou, Chuxin Wang \\ Environmental Art Institute, Environmental Management College of China, Qinhuangdao, 066000, China
}

\begin{abstract}
To strengthen environmental protection, the implementation of ecological sustainable development is the theme of our human development, which leads to the formation of sustainable development concept of green building. This paper firstly introduces the green building system, and then analyzes the energy view, technical view and design view of the green building. The purpose is to strengthen the protection of the environment in the process of construction.
\end{abstract}

Keywords-environmental protection, green building, sustainable development

\section{INTRODUCTION}

Modern science and technology progress and the social productive forces of high-speed development, accelerate the process of human civilization, at the same time, the human society is facing a serious challenge to a series of major environmental and development issues. The problem of population growth, excessive consumption of resources, climate change, environmental pollution and ecological destruction threatens the survival and development of human beings[1].

In the face of the grim reality, people have to re-examine and evaluation we now are regarded as the creed of the urban development view and value system. Many people gradually realize that humanity itself is a natural part of system, it and its supporting environment. In the process of urban development and construction, we must give priority to the ecological environment problems today, and will be placed on the economic and social status and equally important; at the same time, we should further consider the problem of forward-looking, rational utilization of limited resources, the basic connotation of the 1992 United Nations Conference on environment and development proposed by the sustainable development[2].

\section{DESCRIPTION FOR GREEN BUILDING SYSTEM}

Green building system is the benign cycle of ecological system based on the principle of green economic basis, social connotation of green, green technology as the support, a new building system of green environment as a symbol of establishment. In this study, it will be incorporated into the unified research view of nature, people and man-made objects, not only of human life, production and human creation, the natural development of the law but also of human survival, on the relationship of people, nature and architecture[3].
On the target, it is the pursuit of a person (living and production), architecture and the nature of the three coordinated and balanced development. In the method, it advocates design follows the natural. Technically, it advocates the application can promote the virtuous circle of ecological system, no environmental pollution, high efficiency, energy saving and water saving of building technology. The representative of green building is of high efficiency, good environment and sustainable building, adapt to local ecological building without destroying the local ecology. It is seeking a sustainable development mode of construction. It is the system can adjust a positive interaction with the environment, intelligent[4].

\section{BASIC PRINCIPLE OF THE METHOD OF GREEN BUILDING DESIGN}

First, the fundamental purpose of green building is people-oriented, is a living and use of space for people, which makes human requirements are met. Green building compared to ordinary buildings, its function has not changed, but in the original basis of focus on the effective utilization of resources, maximize do turn material resources to good account, keep the balance of nature, suit one's measures to local conditions.

Healthy, comfortable principle of green building should be based on humanity; comfort is the first principle, fundamentally embodied in human care for. Create a healthy and happy life of leisure and work space. It mainly embodies in pollution-free building materials, good ventilation and lighting conditions etc..

Simple, efficient development of the principles of green building should also fully consider the economic benefits; truly achieve the minimum energy consumption and the funds rate. In the design process, should be simple, the principle of saving, for example in the design of door and window position, must the maximum to meet requirements of various indoor layout, try to avoid big changes. In addition, in the selection of energy, but also to the local climate condition and natural resources make full use of all kinds of renewable resources, use as far as possible.

Optimization of overall environmental principles of architecture in the environment is a part of them, should echoes with the surrounding environment, the final purpose of the design is to pursue the optimal environmental benefits. The key point of architectural design for the building and the surrounding is embodied in the ecological balance, coordinated planning, follow the unity of social 
and natural environment fundamentally, which will be the factors configuration, eventually to optimize its overall effect.

\section{THE DESIGN TECHNOLOGY OF GREEN BUILDING}

\section{A. Energy Saving Concept}

Modern architecture is an over reliance on limited energy building. Energy for those of the extensive use of artificial lighting and mechanical air conditioning building means life, and high energy consumption and low efficiency of the construction, is not only an important factor leading to the nervous energy, and is to become the culprit of air pollution. In order to reduce the consumption of non renewable resources, green building advocates adjusting or changing the existing design idea and way, make the building transformed by high energy consumption mode toward low energy consumption, relying on energysaving technology, improve the efficiency of energy use and the development of new energy, make the building gradually get rid of excessive dependence on traditional energy sources, the realization of the use of energy to a certain extent self-sufficiency.

The relevant scholars to study Japan obtained: the overall pollution in the environment related to environmental pollution and the construction industry accounted for $34 \%$, including air pollution, light pollution, electromagnetic pollution. And the protection of the ecological environment of green building is the pursuit of. Therefore, the green building design must penetrate into the whole building life cycle assessment study, building energy consumption situation and its impact on the environment, to establish a comprehensive view of energy. First, must pay attention to the development, optimization of thermal insulation material and structure, improve the building thermal environment performance? As in the air layer inside and outside surface or outer layer structure of the building, using efficient heat emission materials can be most of the infrared ray reflection back, thus the thermal insulation effect on building, as shown in Fig.1.

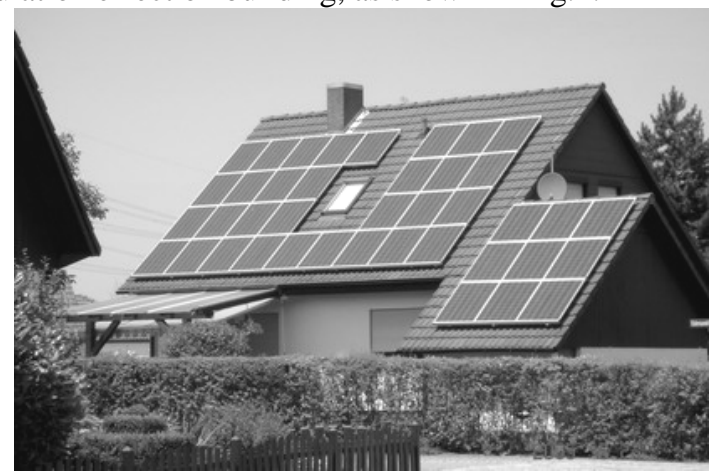

Fig.1: Solar constant temperature type residence

Fundamentally makes the thermal insulation performance of the improved effectively, the essence of the reform of roof and wall, the final performance can strengthen the residential building thermal insulation. Nowadays, the non load bearing wall material model and gradually appeared in people's field of vision, and in the high rise building structure frame is widely used, but most of the multi-storey brick structure housing still is used in traditional solid clay brick, it will not only make land resources consumed, will because the thermal insulation performance of building envelope is relatively weak, and ultimately led to the building energy consumption rate is high, a serious impact to the residents living comfort.

Mixed multi-storey residential structure wall present should focus on the application of new energy-saving loadbearing wall. Make full use of natural lighting and natural ventilation. Natural lighting can count on is inexhaustible, be inexhaustible, it is mainly through the window, the atrium, glass curtain wall and so on means to make indoor lighting adequate. Quality problems in order to effectively improve the building itself lighting, the use of new technology of natural lighting for various full; natural ventilation is mainly through the layout of building group, and its shape design optimization towards and so on, based on the actual situation of the local wind direction to get natural ventilation. Effective use of heat medium means for heat collection. In the system of intelligent building control fully in accordance with their needs to happen for buildings in time to provide the heat required.

\section{B. Design concept Based on Building and Climate}

The development of modern economy and the progress of science and technology, so that human can use mechanical air conditioning to improve the living and working environment, this is the natural human lucky, but against the climate of high energy consumption of building and we paid a huge economic and energy costs, but also increase the ecological environment pollution, but also to a large extent the home ownership and the natural environment artificially separated. In order to overcome the current building model of a negative impact on the people, pay attention to the relationship between climate and green building construction, and will be considered as a basic method of green building design of local climate characteristics, this is a kind of on human comfort requirements and climatic conditions for the system method of gauge construction, namely according to the local climate characteristics by using the principle of construction, physical, rational organization of various architectural factors.

In fact, human beings for the comfort and health needs of the environment, often without the air conditioning equipment can also be satisfied, such as: China's Northern Shaanxi cave at $-20^{\circ} \mathrm{C}$ climate, its interior is surrounded by land, still maintained a comfortable room temperature $15^{\circ} \mathrm{C}$; and housing in the hot dry railing climate, can create shady space in the interior. Therefore, in the green building design view, nature is the main supply, and auxiliary equipment 
system belongs to the second. Therefore, most of the lighting can provide light from the sun, by the flow of the air refrigeration, heating can be obtained through other way from the human natural supplement and office equipment: solar heating, natural ventilation in wind and solar generated buoyancy in water evaporation refrigeration generation.

Consider the design of local climate characteristics is a method that can be used in any technical level because of various factors of climate in the green building is contained as a resource to be considered, make full use of climate resources, improve the utilization of climate resources, is to consider the essence of the design characteristics of the local climate. If the principle and the future of the intelligent technology, information technology, control technology and other energy-saving technology together, they constitute a colorful green building prospect.

\section{View of Technology and Form}

Green building is an active interaction with the environment, intelligent, capable of regulating system. Therefore, it requires building materials and structure of the outer layer, hand as energy conversion interface, the need to collect, conversion of natural energy, and prevent energy loss; on the other hand, the outer layer must have the ability to regulate the climate, in order to eliminate, slow down, or even change the climate fluctuation, make indoor climate tends to be stable, and the realization of this an ideal, to a large extent must depend on the widely used in the construction of the future high technique.

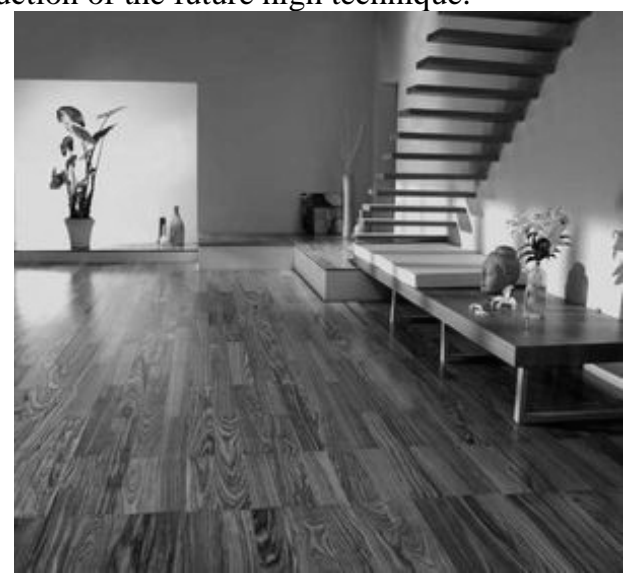

Fig.2: Environmental protection energy-saving type floor

First of all, environmental protection and energy saving materials is necessary for green building, environmental protection, must carry on the existing building materials and energy saving technology assessment, put forward the improvement measures, technology updates, which conforms to the environmental protection, energy-saving requirements. With the development of information technology, automation technology, new energy technology, new materials technology becoming more and more mature, these high technology will be widely used in green building: principles such as building structure may be introduced into the organism, in embedded in concrete, fiber, can constantly monitor the member under load stress condition, self repair concrete can be applied. The surface of the building materials, breathing through the multi functional organization, can purify the air inside the building, and the lower the temperature, the shape memory alloy material can be used for opening and closing adjustments or air conditioning system air inlet louver, automatically adjust the solar light, solar cell surface buildings, can provide heating and lighting needs energy, no matter what the use of technology, green building is always focus on resource conservation, recycling, recycling production etc., as shown in Fig.2.

Secondly, the green building forms must be conducive to the energy collection, building outer will no longer be internal and external line, and will gradually become a multifunctional interface. Green building materials and the form is diverse, especially in the outer layer of material will be highly integrated, high efficiency and multiple functions, and, with the development of high technology, the construction industry will maximize the absorption of all kinds of advanced technology, to create a more suitable for human life, and nature harmony highly high-tech building environment.

\section{CONCLUSION}

Should be combined with China's current economic strength and social overall development level, as soon as possible to determine a magnificent goal and build a set of feasible system frame, so as to make our this generation of immediate interests and long-term interests of the whole mankind together, the overall interests of an area of local interests and the whole world with arise, fair and reasonable share of our earth's limited resources with others. At the same time, maximize prevent resource waste and environmental pollution, so that it may leave a quiet and rich land for future generations, so that human beings can long endure.

\section{ACKNOWLEDGEMENTS}

The research work was supported by 2014 Social Science Development and Research Project of Hebei Province under Grant No.2014041904.

\section{REFERENCES}

[1] Fan, X. L. Sustainable development of building environment. Technology and Economy Market, (12)10, pp.40-42, 2008.

[2] Shen X. F. How to protect historical city building environment. Guangxi Urban Construction, 20(3), pp.83-85, 2009.

[3] Fu, C. Q. Analysis of green energy saving technology in intelligent building. Intelligent Building, 18(6), pp.17-20, 2010.

[4] Shi, Y. J. Research on the problems of environmental protection in construction. Technology of Wind, 23(10), pp.154-155, 2013. 